\title{
Analysis of changes in grain production on fruit and vegetable cultivation areas in Turkey through geographically weighted regression
}

\author{
Kenan Gocer \\ Engineering and Architecture Faculty, Beykent University, Turkey.
}

Received 5 May, 2014; Accepted 11 June, 2014

\begin{abstract}
The main purpose of this paper is to address the question of whether and how farmers have tried to increase agricultural productivity after the regulatory role of governments on the agricultural industry has been reduced due to financial crises. The relationship between agricultural sowing area shifts (grain to fruit, grain to vegetables, vegetables to fruit) were explored by using geographically weighted regression model. This model showed how the decrease of grain sowing areas led to an increase of fruit and vegetable sowing area in Turkey. It was demonstrated that farmers tended to choose more productive agricultural crops in order to address agricultural sustainability problems. Geographical information system data sets regarding the years between 2000 and 2010 were obtained from 923 districts. The results of the analysis showed a strong relationship between changes in grain, vegetable and fruit areas. According to geographically weighted regression, the variation of local coefficients ranged from -0.62 to 0.34 . Because of the productivity factors, grain and vegetable areas have been replaced by fruit production. However, Turkey will be faced with food security problems in the future due to the decrease of grain cultivation. The increasing opportunity for irrigation has had a profoundly important role in shifting from grain to vegetable and fruit production.
\end{abstract}

Key words: Geographically weighted regression, geographical information system, sustainable agriculture, farm policy, food security.

\section{INTRODUCTION}

Statist policies have been replaced by liberal agricultural and trade policies in Turkey after 1980 (Ediger and Huvaz, 2006; Özmucur, 2007; Hasanov et al., 2010; Türkekul and Unakıtan, 2011). The agricultural support policy, which underpinned agricultural policies in Turkey during the planned period between 1960 and 1980, consisted of three main headings: The government's purchase of farmers' products for a base price above the market price; the availability of state subsidies for agricultural inputs such as fertilizer, pesticide and seed; and privileged loan interest rates for farmers (Önal, 2007). After the introduction of liberal policies, the 
Table 1. Agricultural planted areas and changes between 2000 and 2010.

\begin{tabular}{lccc}
\hline Agricultural planted area (decare) & $\mathbf{2 0 0 0}$ & $\mathbf{2 0 1 0}$ & Percent of change \\
\hline Total Agricultural & 263.790 .670 & 243.942 .052 & -7.52 \\
Grain planted & 180.377 .820 & 163.303 .020 & -9.47 \\
Vegetables planted & 9.043 .770 & 8.015 .980 & -11.36 \\
Fruit planted & 26.109 .420 & 30.105 .797 & 1531 \\
\hline
\end{tabular}

regulatory role of the state on prices was left to the market's own operation (Kepenek and Yentürk, 2000).

In the post-1980 period, Turkey frequently experienced economic crises followed by decreases in agricultural supports. Within six years following the financial crisis in 1994, institutions operating in main areas that contributed to the regulation of products such as milk, forage, meat, fish, forest products, tractors and fertilizer were privatized (Önal, 2007). Significant structural transformations were also experienced following the financial crisis in 2001. The most important agricultural change experienced in this period was the initiation of membership negotiations with the European Union (EU). Thus, in Turkish agriculture, a process of comprehensive transformation that included legislative activities aimed at adjusting with the EU Common Agricultural Policies began. After the agricultural reform in 2001, employment in agriculture declined, the share of agriculture in Gross Domestic Product became smaller, internal migration increased as small farmers withdrew from agriculture, and employment opportunities could not be offered to these newcomers with low educational levels in cities (BSB, 2008).

Agricultural production has decreased because of the radical transformations in agriculture in the post-1980 period. The state regulations in favor of farmers in important areas such as meat, fish, forage, seed, fertilizer and tractors has diminished rapidly (Önal, 2007). Important changes have also been observed in the structure of agricultural ownership after the 2001 crisis. While the share of those with an enterprise size of more than 10 ha was $34 \%$ in 2001, it rose to $65.7 \%$ in 2006 (TUIK, 2008). This increase shows that traditional family enterprises have been increasingly vanishing, leaving mainly large enterprises. Further, agricultural crop type has been influenced by this transformation in order to increase productivity. Table 1 demonstrates that in agrıcultural sowing areas there have been some notable changes; while total fruit areas rose, grain and vegetables areas decreased (TUIK, 2011).

Agricultural production is unevenly distributed in Turkey. Farmers living in the coast of Aegean and Mediterranean who have higher income levels concentrated on fruit production. Farmers living in the Southeastern Anatolia who have irrigation opportunities concentrated grain, vegetable and fruit production, since these regions have lower income levels compared to rest of the regions. Large scale irrigation projects change not only agriculture production, but also income structure
(Eraydın, 1992). With regard to agricultural production, any location is linked to the rest of the world through three broad channels; production, trade and climate. That is why agricultural production should be handled in a multifaceted manner. Many studies have tried to answer the question of which factors affect agricultural production and productivity. For example, fertilizer usage (Marinoa et al., 2011; Shengli et al., 2012) efficient irrigation area, (Yujian et al., 2013; Guang-Cheng et al., 2014) drought (Keating and Meinke, 1988; Venuprasad et al., 2008; Chris and Budde, 2009; Ananda et al., 2011; Jana et al., 2013) affects grain production. The main purpose of this paper is to address the question of whether and how productivity plays role in the agricultural production of grains, vegetables and fruits.

\section{METHODOLOGY}

The data between the years 2000 and 2010 was obtained from the Turkish Statistical Institute; 923 districts were used for geographically weighted regression analyses. Districts were taken as the units of analysis. Regions are shown in Figure 1. The year 2000 was selected as the starting point in this research due to the financial crisis, after which striking differences have been observed in spatial organization. ArcGIS was employed as the geographical information system (GIS) program in the analyses. Grain, fruit and vegetables crop variables consist of the total sowing areas (decare) in districts. It was investigated in this study if decreasing of grain crop has a spatial distribution effect or if it contributes to fruit crop and vegetables crop because of the productivity. In this study, in order to explain spatial variability in agricultural production across Turkey, GWR was used instead of OLS.

GWR extends the global regression ordinary least squares (OLS). For each location, regression coefficient can be estimated by using a GWR model (Fotheringham et al., 1996, 2002). GWR method allows for analyzing the spatial variability of the local coefficients of independent variable or variables. Geographically weighted regression is a powerful tool to explain the spatial heterogeneity. OLS creates a regression coefficient which assumes that the relationship between the variables are constant across regions. The OLS can be written as:

$y=\beta_{0}+\sum_{i=1}^{k} \beta_{i} x_{i}+\varepsilon$

Where $\mathrm{y}$ is a dependent variable, $\mathrm{xi}$ are exploratory variables; $\mathrm{k}$ is the number of independent variables; $\beta_{1}$ and $\beta_{0}$ represent and coefficient and intercept respectively; and $\varepsilon$ is the error term.

As a local regression technique, GWR is an extension of global regression technique (Fotheringham et al., 2002). GWR assumes that relationships between the change in grain, vegetable and fruit area may vary over space. It can be formulated as: 


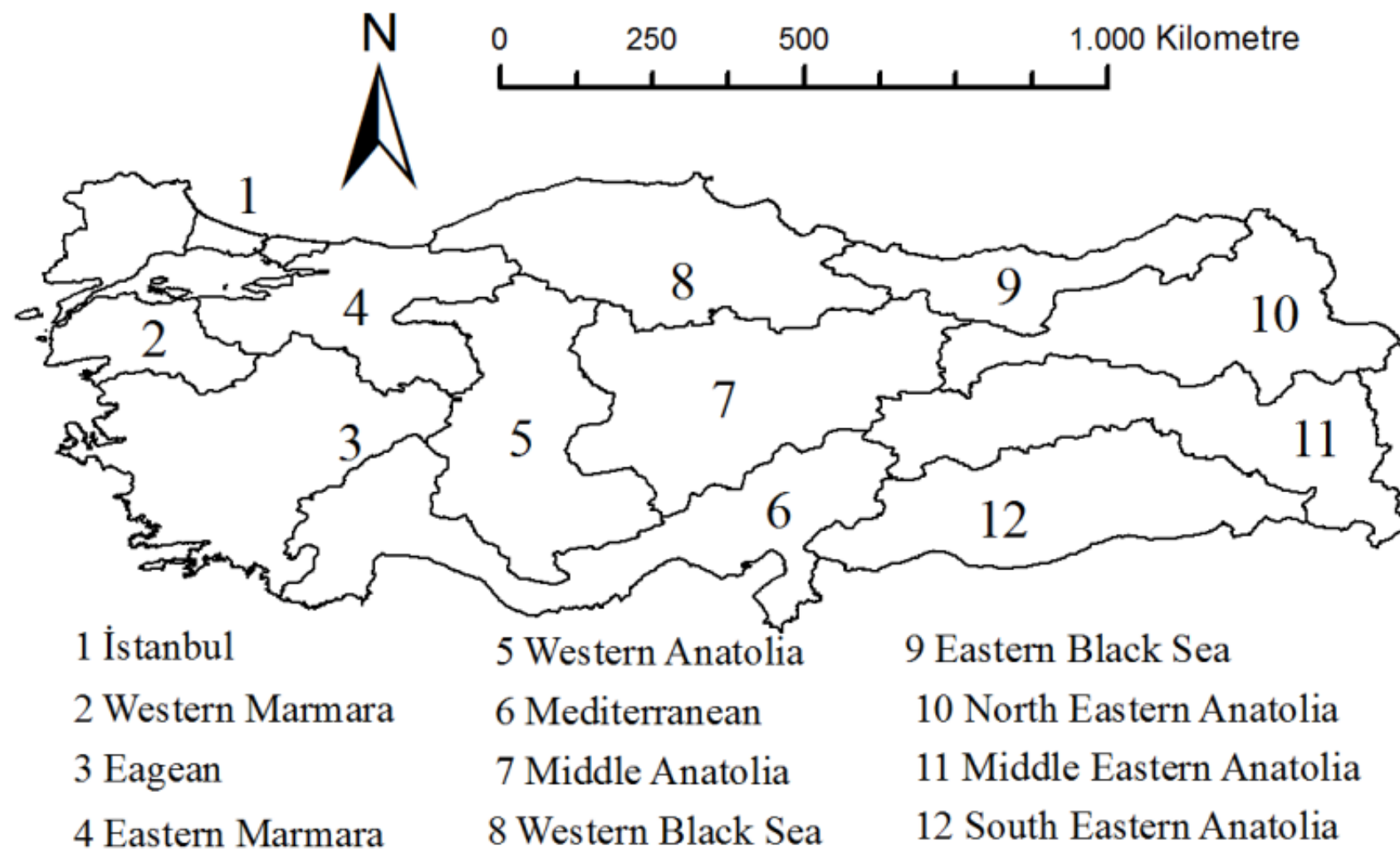

Figure 1. Map of Turkey's regions.

$$
y_{i}=\beta_{0}\left(u_{j}, \mathrm{v}_{i}\right)+\sum_{i=1}^{k} \beta_{i}\left(u_{j}, \mathrm{v}_{i}\right) x_{i j}+\varepsilon_{j}
$$

where $u_{j}$ and $v_{j}$ denote the spatial positions of location $j ; \beta_{0}\left(u_{j}, v_{j}\right)$ is the intercept for location $\mathrm{j} ; \beta_{\mathrm{ik}}\left(\mathrm{u}_{\mathrm{j}}, \mathrm{v}_{\mathrm{j}}\right)$ is the local estimated coefficient for the exploratory variable; $x_{k}$ at point $i$, and $\varepsilon_{j}$ is the random error term at location $\mathrm{i}$.

In case of spatial heterogeneity, local model performance is better than that of the global model. Even if there is a significant relationship between the dependent and independent variable, the result of the global model would be insignificant since there is a positive or negative relation in different regions. In other words, spatially heterogeneous structure can be represented by just one coefficient by a global model, whereas a local model estimates a set of parameters containing independent variable or variables for each spatial unit. During the past five years a considerable amount of literature has been published on GWR in a variety of fields: the regional spillover effect (Rasekhi et al., 2013), land use and water quality (Tu, 2011), agriculture (Su et al., 2012), cancer risks (Gilbert and Chakraborty, 2011), traffic levels (Selby and Kockelman, 2013), migration (Lehtonen and Tykkyläinen, 2010) and grain production (Yang et al., 2013).

\section{RESULTS}

This study is based on the assumption that as long as total agricultural sowing area remains almost constant, when either grain or vegetable sowing areas decrease and fruit area increases in the same district, it can be said that grain or vegetable area are replaced by fruit area.
The maps in Figure 2 were created so that the remarkable difference between 2000 and 2010 in terms of change of grain, fruit and vegetable sowing areas can be seen. Figure 2 also demonstrates the wide range of agricultural sowing areas between districts. Figure $2 a$ shows that grain areas were concentrated in the Middle Anatolia (Figure 1 no: 7) and South Eastern Anatoliain 2000 in Turkey. It can be seen that grain production in Middle Anatolia is dramatically losing its importance. The other important change is that grain area rose in Southeastern Anatolia and Eastern Anatolia (Figure 1 no: 10-11), while it was declining sharply in Middle Anatolia. The grain area decrease in Middle Anatolia will have dramatically effects on Turkey's agricultural production.

The distribution of fruit areas at the coast is more dense than at the center of the Turkey (Figure $2 \mathrm{c}$ and $\mathrm{f}$ ). Fruit areas were concentrated in the Aegean (Figure 1 no:3), western part of Southeastern Anatolia, Eastern part of the Mediterranean (Figure 1 no: 6 ), the Black Sea (Figure 1 no: 8-9) coast and the Eastern part of Marmara (4). Vegetable area is widespread in the Aegean, Mediterranean, western part of Southeastern Anatolia and Western Anatolia (Figure $2 \mathrm{~b}$ and e). The increase in fruit area from 2000 to 2010 across Turkey in contrast to grain area is profoundly important for Turkey's agricultural production process because in fruit is more productive than grain. On the other hand, grain plays a crucial role in food security. 

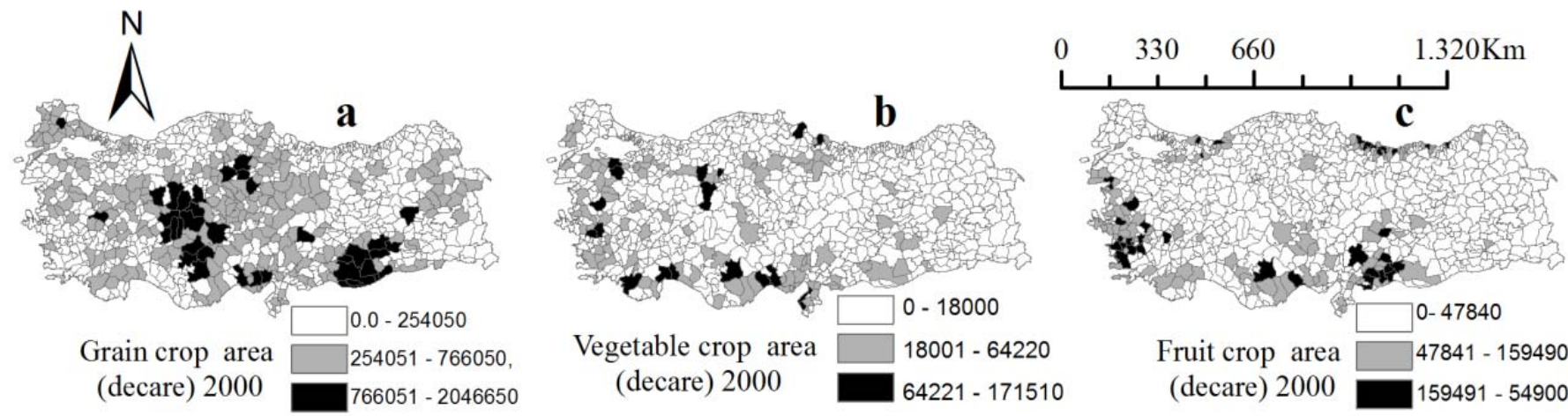

Fruit crop area $47841-159490$ (decare) 2000

$159491-549000$
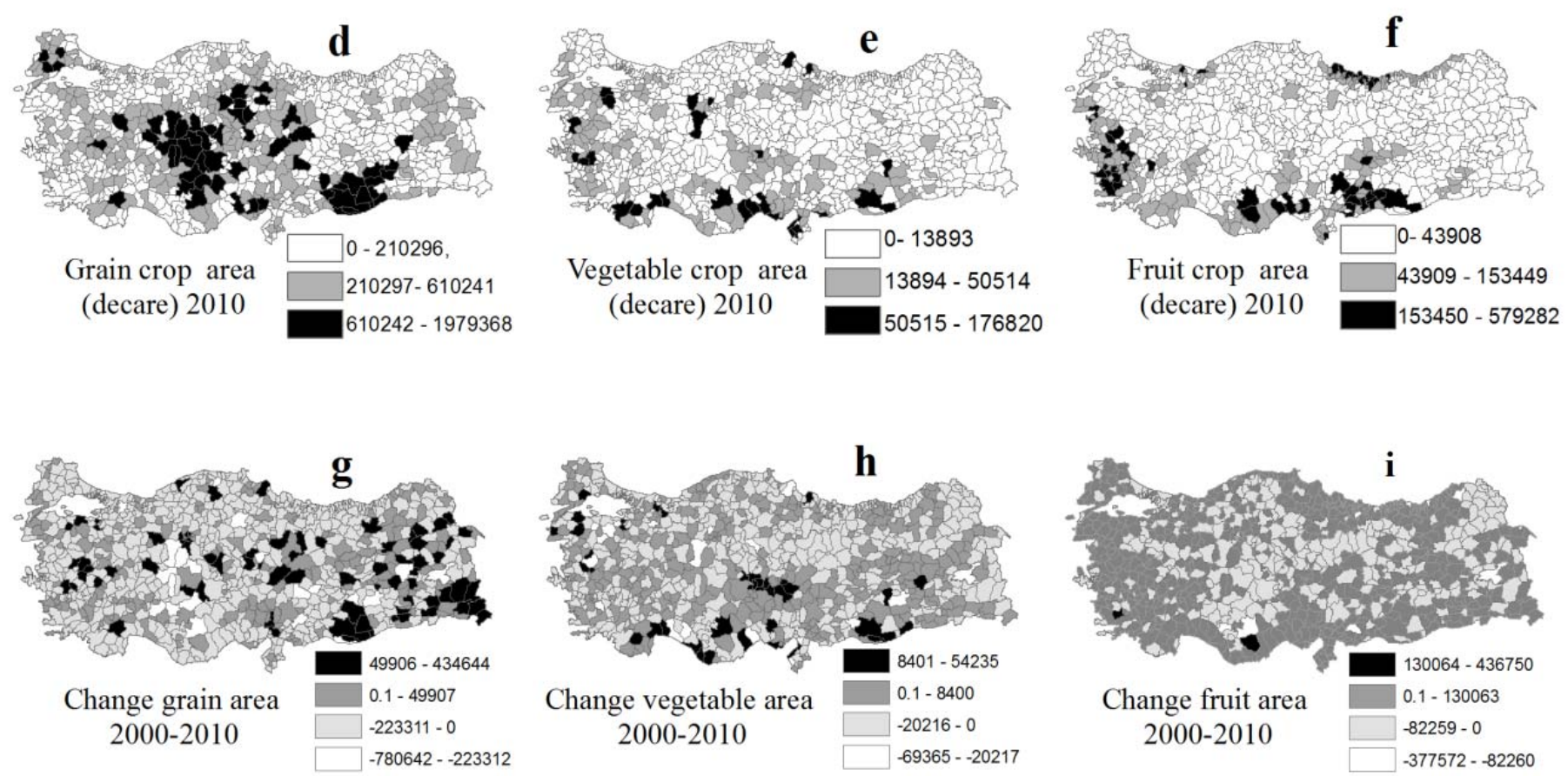

Figure 2. Spatial mapping of grain, fruit and vegetable areas between 2000 and 2010 in Turkey.

Figure 2 can be briefly summarized such that after 2000 among the Turkish agricultural crop types, many transitions such as from grain to fruit production have occurred. In this study, how grain areas are replaced by fruit and vegetable areas is explained by using spatial econometric model. As seen in Figure 2, there are so many spatial transitions from one crop type to another that it can be very difficult to see without using spatial econometric model.

GWR model, which estimates a set of parameters of independent variable for each districts was used to characterize transitions from either grain or vegetable to fruit sowing areas. Local model GWR was performed to determine whether there was a significant spatial nonstationary relationship between the change in grain and fruit area variables over the period. GWR presented better solutions than OLS (Table 2). The AIC results from the GWR model were lower than those from the OLS model, which suggests that the GWR model was a better fit than OLS (Fotheringham et al., 2002; Tuand and Xia, 2008).

The considerable spatial variability in grain, vegetable and fruit sowing area indicates that there is a significant spatial non-stationary relationship between dependent and independent variables. Spatial non-stationery means that the relationship between independent and dependent variables are not constant over space (Fotheringham et al., 2002). The fact that the variation of local coefficients ranges from negative to positive indicates that the relationship between independent and dependent variables is non-stationary. At the same time, the variation of local R-squared, which explains different 
Table 2. Model performance as judged by $\mathrm{AIC}_{\mathrm{GWR}}$ and $\mathrm{AIC} \mathrm{C}_{\mathrm{OLS}}$

\begin{tabular}{|c|c|c|c|c|c|}
\hline Dependent variable & Independent variable & $\mathrm{AIC}_{\mathrm{GWR}}$ & & $\mathrm{AlC}_{\mathrm{GWR}}$ & \\
\hline Fruit & Grain & $\mathrm{AIC}_{\mathrm{GWR}}$ & 21543,9 & $\mathrm{AIC}_{\mathrm{OLS}}$ & 21554 \\
\hline Vegetable & Grain & $\mathrm{AlC}_{\mathrm{GWR}}$ & 18824,1 & AlCols & 19036 \\
\hline Vegetable & Fruit & $\mathrm{AlC}_{\mathrm{GWR}}$ & 18898,4 & $\mathrm{AlC}$ ols & 19045 \\
\hline
\end{tabular}

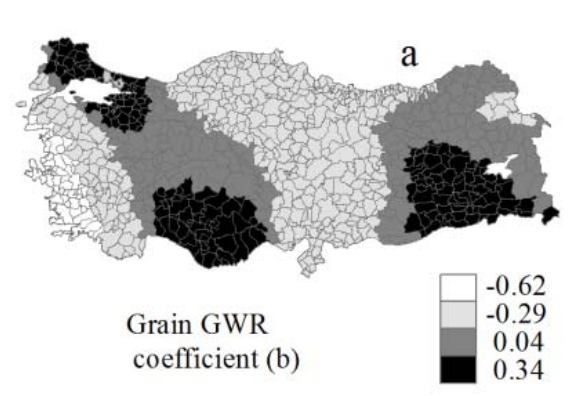

Dependent variable: Changing Fruit Area

Independent variable : Changing Grain Area
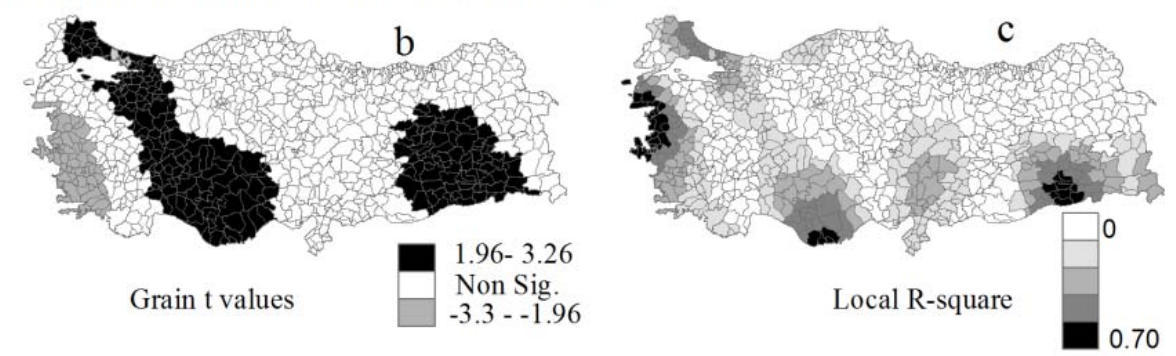

Dependent variable : Changing Vegetable Area

Independent variable : Changing Grain Area
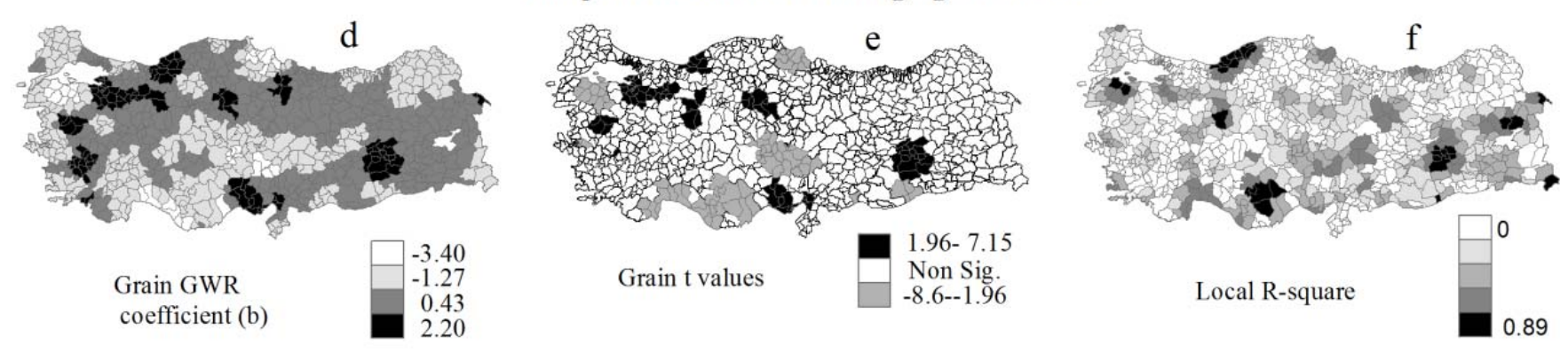

Dependent variable: Changing Vegetable Area

Independent variable : Changing Fruit Area
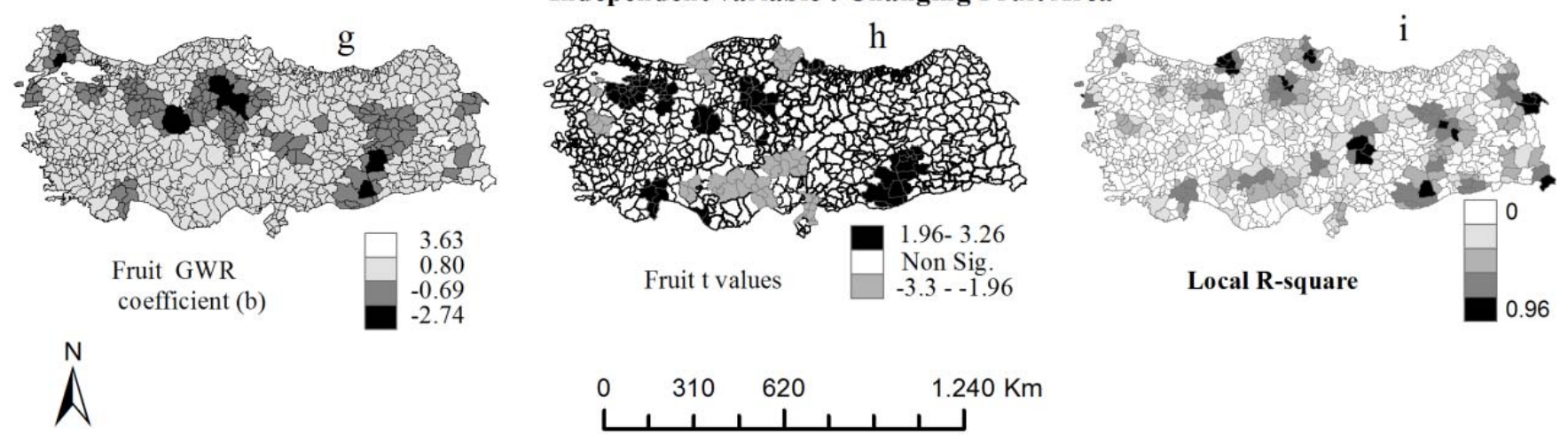

Figure 3. Spatial distribution of local coefficients, R-squared and t-statistics from the GWR. T-values are significant in some districts at a 0.05 level (t-values above 1.96 and lower than -1.96).

localization, shows the relationship between grain, vegetable and fruit variables (Table 3 ). Figure 3 shows the results of the GWR analysis that was performed to determine the relationship of spatial variability between changing grain, vegetable and fruit sowing areas.

Here, we show how there is a relationship between the agricultural sowing types shift by taking into account GWR results. The share of fruit among arable areas 
Table 3. Variation of local R-squared.

\begin{tabular}{llllll}
\hline Dependent variable & Independent variable & Coefficient & & & \\
\hline Fruit & Grain & Grain coefficient & $-0.64-0.34$ & Local R-squared & $0.0-0.70$ \\
Vegetable & Grain & Grain coefficient & $0.06-2.67$ & Local R-squared & $0.0-0.89$ \\
Vegetable & Fruit & Fruit coefficient & $-2.74-3.63$ & Local R-squared & $0.0-0.96$ \\
\hline
\end{tabular}

increased in all regions. Figure $3 a$, $d$ and $g$ show the spatially varying coefficients. In those maps, white and light-gray district clusters indicate a negative relation between independent and dependent variables and darkgray and black colors represent that both independent and dependent variables increased. Some of the t-values that are represented by white color in the Figure $3 \mathrm{~b}$, e and $\mathrm{h}$ were insignificant at a 0.05 level (t-values above 1.96 or lower than 1.96). Figure 3c, $f$ and $i$ show Rsquared variables for each district. There are of course black and dark gray clusters, indicating a strong relationship between the variables.

Grain coeffients range from -0.62 to 0.34 (Figure 3a). The fact that the variation of local coefficients range from negative to positive account for relationships between changing grain and fruit sowing area spatial heterogeneity distributions. Positive coefficient values are found in Mediterranean, Southeastern Anatolia (SEA) and western Marmara. Considering fruit productivity, those regions have advantages of sustainable development of agricultural areas. In addition, they have a relative advantage in terms of irrigation systems. In particular, the SEA region is the site of the important Southeastern Anatolia irrigation project that is likely to be a contributing factor in increasing both grain and fruit area (Akpınar and Kaygusuz, 2012; Çelik and Gülersoy, 2013).

Black color clusters in Figure $3 a$ reflect how farmers meet sustainability conditions after government regulations in the agricultural industry have been reduced. The negative coefficients are highly concentrated in the coast of Aegean. This negative spatial relationship is evidence of how the grain area was replaced by fruit area. The reason why the agricultural area shifted from grain to fruit is likely due to irrigation opportunities. Another reason in SEA is that farmers have large arable areas which have both sunshine duration and irrigation advantages. The reason that fruit area is increasing while grain area is decreasing is based on the fact that fruit is definitely more productive than grain.

Unlike fruit, vegetable and grain planting and production cycle is less than 1 year. Since it takes about 3 to 10 years to reach the first fruit harvest, it is very difficult for poor farmers to shift from grain to fruit. Even if poor farmers have enough arable land to produce fruit, they have to continue to crop grain. Apart from the Black Sea region, regions in the coast of Turkey have relatively higher income levels. Therefore, in those regions, agricultural sowing areas have shifted from grain to fruit smoothly.

Figures $3 d$, e and $f$ show the results of the GWR analysis that was performed to show the relationship of spatial variability between changing grain and vegetable areas. Grain coefficients variable ranged from -3.40 to 2.20 (Figure $3 \mathrm{~d}$ ). Therefore we can say that relationship between changing grain and vegetable area spatially heterogeneously distributed. Negative coefficients, concentrated on the coast of Aegean, Eastern Black Sea, Mediterranean, Southwest Marmara. Middle Anatolia and Southeastern Anatolia are a very clear demonstration of how the grain area was replaced by vegetable. Shift from grain to vegetable is easier than shift from grain to fruit because of the long amount of time to first harvest for fruit cultivation. In this reason negative coefficients between the grain to vegetable are more widespread than grain to fruit. The reason that grain production is being replaced by vegetables in the coastal regions of Turkey is that those regions have irrigation advantages compared to the rest of the Turkey.

Figure $3 \mathrm{~g}$ shows that grain coefficients variable ranged from -2.74 to 3.63 . Coefficients ranging from negative to positive indicate how well the local regression model is obtained. Negative coefficients represent shifts from vegetable to fruit and positive coefficients represent that both vegetable and fruit increased. The negative relationship between vegetable and fruit area is concentrated in the SEA, north of Mediterranean, north of Aegean and west Black Sea. Because both vegetable and fruit need irrigate systems, the shift from vegetable to fruit is relatively easily. Significant positive relationships suggest that changing vegetable sowing area from 2000 to 2010 is associated with higher changing fruit sowing area.

\section{DISCUSSION}

Many farmers are beginning to recognize the need to increase agricultural productivity. In order to cope with and adapt to agricultural productivity challenges, farmers prefer fruit production instead of grain. Farmers attempted to overcome and adapt after new economic crisis conditions by raising sustainability limits through new spatial organizations. In the coastal regions of Turkey, it is obvious that agriculture has shifted from grain area to fruit area. The reason why there is a spatial 
transition from grain and vegetable area to fruit area is based on the fact that fruit productivity is much higher than vegetable and grain. There is a controversial situation here in that this process may lead to new food security problem. The shift from grain to fruit may solve the farmers' sustainable agriculture problem but cause a food security problem for the nation because grain is such an essential food.

Fruit agriculture crop requires high amount of water compared to grain areas. Middle Anatolia has disadvantages in irrigated agriculture compared to the coast of Turkey. SEA is one of the poorest regions in Turkey. Accordingly, there are many districts in which per capita income is far below the average in the east of Turkey. In 2010, the richest province (Istanbul) had a per capita income more than 3 times than that of the poorest provinces (Mardim, Batman, Siirt, Sirnak). The probability that in the SEA region, positive agricultural changes will contribute towards catching up to wealthier provinces is very high.

\section{Conclusions}

The purpose of this study was to determine how farmers have tried to increase agricultural productivity. This paper shows that agricultural productivity can play an important role in grain production. One of the more significant findings to emerge from this study is that Turkey's types of agricultural production have changed drastically. Striking evidence shows that grain production is moving from the center of Turkey to the east and southeast. The second major finding was that agricultural productivity can play important role in the shift from grain and vegetable to fruit production. There is a spillover effect between agricultural production types, because grain is crucial for human life. The decline of government support for farmers and economic crises make sustainable agriculture extremely difficult. It can be said that sustainable agricultural production is at risk in Turkey since droughts have increased in central Anatolia, which is an important region for grain production. It is understood that farmers prefer fruit, but we do not know what kinds of fruit have replaced grains and vegetables. Further research needs to be done to establish how climate conditions influence types of agricultural production and to analyze which kind of fruit has been preferred in order to more comprehensively characterize the current situation and trends.

\section{REFERENCES}

Akpınar A, Kaygusuz K (2012). Regional sustainable water and energy development projects: A case of Southeastern Anatolia Project in Turkey. Renew. Sustain. Energy Rev. 16:1146-1156. http://dx.doi.org/10.1016/j.rser.2011.11.015

Ananda N, Vadlani PV, Prasad PVV (2011). Evaluation of drought and heat stressed grain sorghum (Sorghum bicolor) for ethanol production. Ind. Crops Prod. 33:779-782. http://dx.doi.org/10.1016/j.indcrop.2011.01.007

BSB (2008).2008 Kavşağında Türkiye siyaset iktisat ve toplum. Yordam, Istanbul. pp. 169-183.

Chris F, Budde ME (2009). Phenologically-tuned MODIS NDVI-based production anomaly estimates for Zimbabwe. Remote Sensing of Environment. http://dx.doi.org/10.1016/j.rse.2008.08.015

Çelik MA, Gülersoy AE (2013). An examination of the effects of Southeastern Anatolia Project on agricultural patterns changes using remote sensing. J. Int. Soc. Res. 28(5):46-54.

Ediger VS, Huvaz O (2006). Examining the sectoral energy use in Turkish economy (1980-2000) with the help of decomposition analysis. Energy Conver. Manage. 47(6):732-745. http://dx.doi.org/10.1016/j.enconman.2005.05.022

Eraydın A (1992). Post-FordizmveDeğişenMekansalÖncelikler. ODTÜ, Ankara.

Fotheringham AS, Charlton ME, Brundson C (1996). The geography of parameter space: and investigation into spatial non-stationarity. Int. J. GIS. 10:605-627.

Fotheringham AS, Brunsdon C, Charlton M (2002). Geographically Weighted Regression: The Analysis of Spatially Varying Relationships. Wiley, Chichester.

Gilbert A, Chakraborty J (2011). Using geographically weighted regression for environmental justiceanalysis: Cumulative cancer risks from air toxics in Florida. Soc. Sci. Res. 40:273-286. http://dx.doi.org/10.1016/j.ssresearch.2010.08.006

Guang-Cheng S, Sheng D, Na L, Shuang-En Y, Ming-Hui W, Dong-Li S (2014). Effects of controlled irrigation and drainage on growth, grain yield and water use in paddy rice. Eur. J. Agron. 53:1-9. http://dx.doi.org/10.1016/j.eja.2013.10.005

Hasanov M, Ayşen A, Telatar F (2010). Nonlinearity and structural stability in the Phillips curve: Evidence from Turkey. Econ. Model. 27(5):1103-1115. http://dx.doi.org/10.1016/j.econmod.2010.03.009

Jana K, Greg M, Vincent V, Peter C, Graeme LH (2013). Drought stress characterization of post-rainy season (rabi) sorghum in Indi. Field Crops Res. 141:38-46. http://dx.doi.org/10.1016/j.fcr.2012.10.020

Keating BA, Meinke H (1988). Assessing exceptional drought with a cropping systems simulator: A case study for grain production in Northeast Australia. Agric. Syst. 3:315-332.

Kepenek Y, Yentürk N (2000). Türkiye Ekonomisi. RemziKitapevi, Isanbul. pp. 197-198.

Lehtonen O, Tykkyläinen M (2010). Self-reinforcing spatial clusters of migration and socio-economic conditions in Finland in 1998-2006. J. Rural Stud.

26:361-373 http://dx.doi.org/10.1016/j.jrurstud.2010.02.003

Marinoa S, Tognettib R, Alvinoa A (2011). Effects of varying nitrogen fertilization on crop yield and grain quality of emmer grown in a typical Mediterranean environment in central Italy. Eur. J. Agron. 34:172-180. http://dx.doi.org/10.1016/j.eja.2010.10.006

Önal NE (2007). 1980 sonrasıdevletpolitikalarınınTürkiye'nin tarımsal dönüşümüne etkileri. Marmara Universitesi. Unpublished PHD thesis.

Özmucur S (2007). Liberalization and concentration: Case of Turkey. Q. Rev. Econ. $\quad$ Financ. http://dx.doi.org/10.1016/j.qref.2006.08.005

Rasekhi S, Anousheh S, Ranjbar H, Moghimi M (2013). Regional spillover research and development investment: A geographically weighted. Afr. J. Bus. Manage. Regression Approach 7(33):32123219.

Selby B, Kockelman KM (2013). Spatial prediction of traffic levels in unmeasured locations: applications of universal kriging and geographically weighted regression. J. Transp. Geo. 29:24-32. http://dx.doi.org/10.1016/j.jtrangeo.2012.12.009

Shengli G, Hanhua Z, Tinghui D, Jinshui W, Wenzhao L, MingdeH., Yong L, Keith JS (2012). Winter wheat grain yield associated with precipitation distribution under long-term nitrogen fertilization in the semiarid Loess Plateau in China. Goderme 189-190:442-450. http://dx.doi.org/10.1016/j.geoderma.2012.06.012

Su S, Xiao R, Zhang Y (2012). Multi-scale analysis of spatially varying relationships between agricultural landscape patterns and urbanization using geographically weighted regression. Appl. Geo. 32:360-375. http://dx.doi.org/10.1016/j.apgeog.2011.06.005

Tu J (2011). Spatially varying relationships between land use and water 
quality across an urbanization gradient explored by geographically weighted regression. Appl. Geo. 31:376-392. http://dx.doi.org/10.1016/j.apgeog.2010.08.001

Tuand J, Xia ZG (2008). Examining spatially varying relationships between land use and water quality using geographically weighted regression I: Model design and evaluation. Sci. Total Environ. 407:358-378. http://dx.doi.org/10.1016/j.scitotenv.2008.09.031; PMid:18976797

TUIK (2008). The research of agricultural business structure, number: 196 newsletter.

TUIK (2011). Statistical Indicators, 1923-2010. Turkish Statistical Institute, Ankara.

Türkekul B, Unakıtan G (2011). A co-integration analysis of the price and income elasticities of energy demand in Turkish agriculture. Energy Policy 39:2416-2423. http://dx.doi.org/10.1016/j.enpol.2011.01.064
Venuprasad R, Sta Cruz MT, AmanteM, Magbanua R, Kumar A, Atlin GN (2008). Response to two cycles of divergent selection for grain yield under drought stress in four rice breeding populations. Field Crops Res. 107:232-244. http://dx.doi.org/10.1016/j.fcr.2008.02.004

Yang Y, Tong X, Zhu J (2013). A geographically weighted model of the regression between grain production and typical factors for the Yellow River Delta. Math. Comput. Model. 58:582-587. http://dx.doi.org/10.1016/j.mcm.2011.10.062

Yujian Y, XueqinT, Jianhua Z (2013). A geographically weighted model of the regression between grain production and typical factors for the Yellow River Delta. Math. Comput. Model. 58:582-587. http://dx.doi.org/10.1016/j.mcm.2011.10.062 